\title{
Le Morte d'Arthur as Literary Remediation Process to RPG Game
}

\author{
Lis Yana De Lima Martinez \\ Ph.D Student of Comparative Literature and Theory \\ Instituto de Letras/ Universidade Federal do Rio Grande do Sul \\ Porto Alegre, Rio Grande do Sul, Brazil \\ yana.flafy@gmail.com
}

Vinicius De Moraes

Master Student of Comparative Literature and Literary Theory and Criticism

Instituto de Letras/ Universidade Federal do Rio Grande do Sul

Porto Alegre, Rio Grande do Sul, Brazil

xx_vinicius@hotmail.com

Sandra Sirangelo Maggio

Professor at Universidade Federal do Rio Grande do Sul

Department of Modern Languages

Instituto de Letras/ Universidade Federal do Rio Grande do Sul

Porto Alegre, Rio Grande do Sul, Brazil

sandramaggio01@gmail.com

\section{Abstract}

This article presents a proposal for the elaboration of an RPG game with board support based on the remediation of literary narratives and which is thought both for use in the classroom, as 
a didactic tool, but understood essentially as a playful activity. For that, we first start an observation about the act of playing and what it means in society and in linguistic terms. Subsequently, we are concerned with defining what a game is so that we can effectively present the proposal. To better exemplify it, we present as an example the remediation of Arthurian legends from Le Morte d'Arthur, by Thomas Malory, a project that we have previously tested. The discussion about the behaviour of games then runs through authors such as Johan Huizinga (1980) and Jesper Juul (2005).

Keywords - Games, RPG, didactic proposal, literary narratives.

Human existence passes through several daily practices. They are commonplace activities that we have maintained since the beginning of homo sapiens existence on Earth. Since they are so naturalized, they seem not even worth noticing or commenting about. Lighting the stove (fire handling), speaking, singing and, certainly, playing are good examples of this natural daily life activities.

As Johan Huizinga (1980) observed, playfulness, still in the sense of play, would be older than culture, since culture is a concept linked to the human and we have known that many animals have the habit of playing. Therefore, we could still, as Huizinga suggests, say that the act of playing is not exclusivity or a human invention, but a natural act shared with animals. We could also consider that it is something that ties us to our animal ancestry.

Nonetheless, Huizinga (1980) warns us that even in its less complex character, the game permeates meaning, because it is an action that exceeds the immediate needs of everyday life, giving reason and foundation to a non-essential action. Thus, we should understand playing as natural. Yet, we should move away from a conception of instinctual action, because "however we may regard it, the very fact that play has a meaning implies a nonmaterialistic quality in the nature of the thing itself' (HUIZINGA, 1980, p.1). 
Another interesting feature of the act of playing is that it runs through the observations of Aristotelian mimèsis and anagnórises. Right at the beginning of Poetics, Aristotle proposes that since childhood, human beings have tended to imitate, resorting to mimesis in its early stages of learning. Anagnórises, on the other hand, evokes the discovery of the resolution of facts. In the case of Poetics, the discovery occurs at the end of the play, when the viewers respond to their initial anxieties. Northrop Frye even adapts this question to the novel: "When a reader of a novel asks, 'How is this story going to turn out?' He is asking a question about the plot, specifically about that crucial aspect of the plot which Aristotle calls discovery or anagnorisis" (FRYE, 1973, p.52). It could be said that the player behaves in the same way as the reader and the spectator. When the game starts the players are not sure how it is going to end.

Considering mimesis as a knowledge acquisition practice that manifests itself in early childhood, it is also interesting to note that Johan Huizinga ponders a link between the playful act and childhood. Huizinga (1980, p.199) states that to play a game, men and women must play like children. Thus, we could say that there is a cut-off age range for games only while the human being is maturing, after that, as an adult, she or he must have all the necessary skills for all games, as she or he will mimic the child they once were.

All these interactions, however, do not occur without a brief distinction between playing and gaming, without rules and without the parties effectively deciding to play their proper roles in the action. The first is probably an issue that permeates linguistic rather than playful demands and controversies. This is because the verbs play and game are manifested differently in different languages. Unfortunately, we may not stick to more significant examples since we do not wish to embark on these paths. However, we can make a brief observation of how these verbs behave in the Portuguese language. Portuguese dictionaries commonly associate the two words (jogar and brincar) with the idea of fun and, not infrequently, we find one verb being 
synonymous with the other. In the Michaelis dictionary (2015), however, we came to find a minimum distinction: brincar would mean "to handle (...) distractedly" or say something in a joke tone, saying something far from seriousness, while jogar would be "fun or exercise for children in which they demonstrate their ability, dexterity or cunning".

It is necessary to note that we have brought here a minimum distinction between the words play and gaming, but not necessarily between the verbs brincar and jogar. The lack of a specific definition is considered by us more as a possibility of comprehensiveness than a conceptual flaw. Therefore, in this article, it is likely that the two terms are provided as synonyms for the same concept, comprising the action and the product of the action (the game) within the postulates of Huizinga (1980). In other words, we understand that both playing and gaming encompass an activity that proposes meaning and playfulness.

Next, we bring up another issue that is as important as the first: the definition of what a game is. Only after this brief discussion, we may present our proposals for creating games based on literary works to be used with students.

Game

Many theorists and critics used the assumptions of play, or even specific games, to construct their observations and theories, such as Wolfgang Iser (2011). However, none of them observed or bothered to conceptualize what a game effectively is. They just discussed it as a self-explanatory metaphor. Not even Johan Huizinga was destined for such a study, preferring to observe the action (not the products), and how this action was allocated within society and history.

This, however, is not to say that the process of conceptualizing playing was never undertaken. It was, but relatively late, if we consider the elderly relationship that games had established with humanity. 
In this article, we apply some Jesper Juul's postulates as a compass, considering that he is the one who best understands and embraces all the definitions of what a game can be. Having observed a series and meticulous reading of previous attempts, Jesper Juul (2011) presents that games are outlined from five main characteristics:

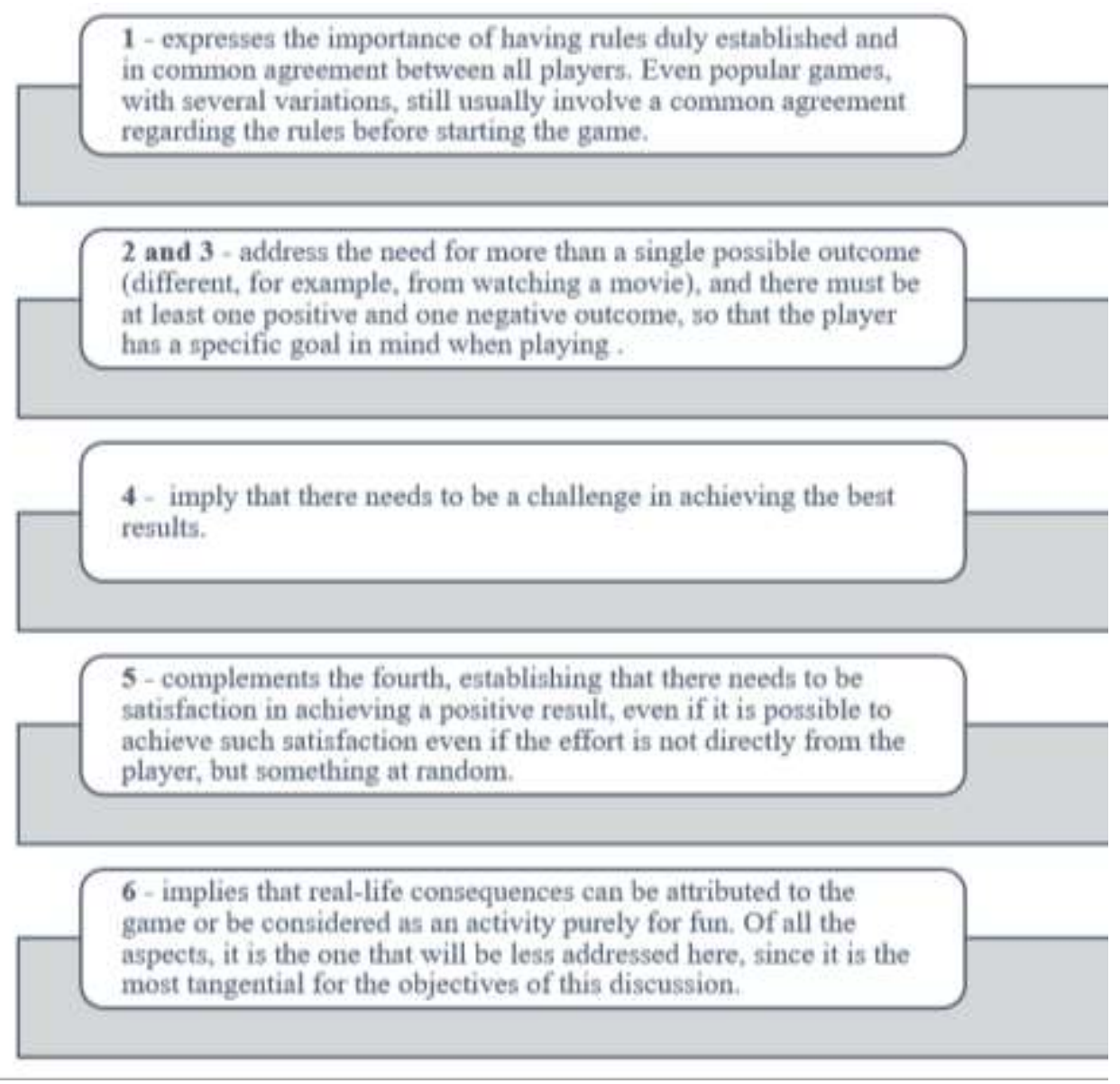

Image 1: Most important aspects of the rules listed by Juul (2011). Source: designed by the authors

Another aspect raised by Juul (2011) that interests our observations is the relationship that is established between the rules and the fiction that makes up a game. Although we understand, as expressed by many theorists, that games do not essentially need to present a fictional character (FRASCA, 2003a; 2003b), we believe that there is a remarkable connection 
between the two. Even the oldest games have an associated fictional aspect, such as senet, decks and chess. A consequence of the fictional aspect is that of transformation since two games that have the same rules can be incredibly different through their fictional aspects (JUUL, 2011, p. 15). Likewise, fiction is often linked to the rules of the game. What would it be like to walk around a board if there was no need to solve a robbery or murder in $221 \mathrm{~B} \mathrm{Baker}$ Street: The Master Detective Game? It can be said that the main point in which games differ from other media is interactivity. While the audience's interaction with other media takes place in an introspective context, Bolter and Grusin (1999) argue that games present another possibility, as the individual's response to the work is shown within itself. Board games are defined especially according to the fact that they include the use of a board and pieces manipulated by the players. This type of game is one of the oldest. Examples of board games have been represented in Egyptian paintings from the 12th century B.C. (JUUL, 2011). It is also common for them to represent specific themes such as the war between kingdoms (chess), cultivation of the plantation (mancala), moral education (stairs and snakes) etc. Some, in fact, already demonstrate the pedagogical potential of board games.

The main differential of board games in contrast to, for example, Brazilian The choice of this work, at the expense of all others, is made for some reasons. The first one is because it is medieval literature, which allows seeing the works with a different perspective from later works such as, say, The Mists of Avalon, by Marion Bradley. Through Malory, it is also possible to approach medieval history and culture in a more direct way, which is more beneficial for the game. Another reason is that it is an English Literary work. Although the legend of King Arthur was influential across Europe (as in French poetry) and was influenced by other legends and myths of the period (such as those of Charlemagne's paladins and possibly even Nordic legends), the fact is that if his roots are British, and the legends themselves often focus on a Breton kingdom. Finally, Le Morte d'Arthur is a work with an enormous amount of 
content, which will be duly commented on in chapter 1. which facilitates the adaptation process by having more story options to be used as the basis of the game. With the variety of stories written by Malory, as well as the episodic character of the stories in the book, it becomes easier to select those that best adapt to an interactive format, as opposed to works that have a more fixed continuity, where the stories are more connected to each other. ${ }^{1}$ is in the presence of a set of tools that represent the game, the playable pieces, and the board. This shows an interesting relationship between the board games and the boards themselves, in which the objects are secondary since a piece can be any object agreed between players as a piece, and yet, something imperative. The board and pieces must provide a set of opportunities for representing the fictional aspects of the game and for its gameplay.

On a similar note, there is a similar genre of games, similar to board games and more recent: RPG. This genre, however, evolved differently from the genre that originated it, focusing on another aspects and, as such, the board tool is no longer an essential aspect for gameplay. Its gameplay is based on a group of players who join in a place to build and play a story together. Thus, one of the players takes on a leadership role, as he will create the general storyline while the other players create the characters that will be part of the story. This leader is called Dungeon Master. The game progresses as the other players, playing the characters they had previously created, advance in the story built by the master.

As a genre, RPG stands out precisely for having the creation of its aspect as one of the players' functions. This role of authorship also has the potential of having a positive impact on the way the game relates to the players' emotional investment since the RPG revolves around the proposal of each player to put herself or himself in the role of one of the protagonists of the story. The victories and fails that players experience are also analysed from the perspective of

\footnotetext{
1 These are Brazilian games that consist of the formation of a circle, with the participation of children,
} who sing songs of a folk character, following choreographies. 
the characters, who go through such events. In this case, there is not only the emotional impact of winning or losing in a game but also the emotional relationship of accompanying a beloved character through a journey. In this regard, the RPG is particularly close to the literature regarding the emotional investment of those who interact with the media, but it distances itself from literature since it offers the opportunity for the player to influence the story.

Therefore, we believe that using games as a method to explore a topic is a more interesting strategy, at least in a well-established teaching project. Next, we elaborated a possibility that aims to remediate literary themes for the creation of RPG games to be applied in schools.

\section{Proposition}

We propose that the teacher could build an RPG game centred on a board. This game has plans to bring topics covered by literature. Since it is affiliated with the board and RPG genres, it is suggested that the teacher should select pieces of literature that bring in their narrative the characteristic of movement, of the journey. Some examples of works that could easily be remediated would be the epics Odyssey and Aeneid, or the novels $O$ cavaleiro da Dinamarca, by Sophia de Mello Breyner Andresen, and Le Morte d'Arthur, by Thomas Malory.

Since it is a game for classroom purposes, the first thing to observe is the limitations. The first one concerns time: ideally, the maximum that a game should take would be about 30 minutes, as we should consider class periods of 45 to 50 minutes. This means making use of shorter stories and more direct challenges. Likewise, it is also important that the game is relatively simple, to facilitate its understanding and, consequently, its gameplay. To favour interactivity, players must also have the freedom to be able to "play" with the stories, not 
limited to the original text. They must be able to create their own version, with different characters or even a different ending than the one appears in literary works.

Finally, it is worth considering the general characteristics of the game. Next, we apply our proposition in the remediation of Thomas Malory's Le Morte d'Arthur. Understanding Le Morte d'Arthur, the board in question represents Camelot, and each student, as a player, assumes the role of a member of the Round Table. If the game were to remediate the Odyssey, each player could be one the seamen and the board could be the seas of Greece, for example.

The choice of this work, at the expense of all others, is made for some reasons. The first one is because it is medieval literature, which allows seeing the works with a different perspective from later works such as, say, The Mists of Avalon, by Marion Bradley. Through Malory, it is also possible to approach medieval history and culture in a more direct way, which is more beneficial for the game. Another reason is that it is an English Literary work. Although the legend of King Arthur was influential across Europe (as in French poetry) and was influenced by other legends and myths of the period (such as those of Charlemagne's paladins and possibly even Nordic legends), the fact is that if his roots are British, and the legends themselves often focus on a Breton kingdom. Finally, Le Morte d'Arthur is a work with an enormous amount of content, which will be duly commented on in chapter 1 . which facilitates the adaptation process by having more story options to be used as the basis of the game. With the variety of stories written by Malory, as well as the episodic character of the stories in the book, it becomes easier to select those that best adapt to an interactive format, as opposed to works that have a more fixed continuity, where the stories are more connected to each other.

As this game is formatted for the classroom, we chose to extinguish the figure of the master. Therefore, the teacher must create a group of stories that are self-explanatory, and the players must together choose which one will be played. To streamline the process, we suggest that the choice be made by lot. To run the game, students need to travel around Camelot, 
visiting different locations and working together to solve the main plot. The purpose of the game is for players to have significant contact with the theme - in this case, the Arthurian legends - and, consequently, with subjects that touch it - medieval literature, the geography of England, culture, etc. - and thus gain greater interest in this genre. It is important to note that, for the game to work, it must be designed as such, that is, it must first work in isolation, only as a game.

The didactic quality must be thought during the creation, but it must not surpass the gameplay. In other words, the games as a teaching tool cannot suppress its function as a game. Anyway, the premise of the game is already an invitation to the players to know a little more about the remediated stories and, with the mediation of a teacher, it is possible to expand the discussions about aspects and themes of these works. Keeping in mind the general aspects of the game, it is possible to start discussing its details. As a starting point, it is advisable to analyse the rules of the game, since it is about them that all other aspects apply. At the same time, however, because it is the basis of the game, it is also the one that has the most indirect relationship with the reference material. The proposal revolves around both a board, which demarcates the players' progress through a location, as well as around a more narrative side, where events can unfold in different ways depending on the choices made by the players. Therefore, the central goal of the game is to fulfil a certain set of objectives (main and secondary), determined by the selected story, which will be found in specific points of the kingdom, where the players need to go to fulfil them.

To achieve these goals, each player selects a specific character, who will come with a certain skill set, standing out in some tasks. These characters will represent the players within the game and will be the way to interact with the story. Although technically, it is possible to create your own characters (the characteristics are simple enough to allow this), the game already proposes ready-made characters. In the case cited here, these characters are members 
of Malory's round table. All these characters can be summed up in a set of five attributes, characteristics that vary in values from 1 to 5 , defining how skilled the character is in that aspect, and a skill, which provides some special way to interact with the fictional world. Each character has a distinct ability, but the attributes always remain the same: bravery, loyalty, faith, courtesy and cunning. Characters can either be created by players or characters from narrated narratives can be personified. Finally, after having the characters and the story defined, the players start the game itself. This is done through rounds, in which each player crosses a certain number of spaces on the board (determined in a roll of a six-sided die) towards some of the main points of the map (they are prominent places in Arthurian stories).

The player, at the end of his move, is faced with an event, depending on where to stop. If they have reached any of the main points, they are faced with the main event, where they will receive the opportunity to fulfil some major objective and advance the story or fulfil a minor objective, which will facilitate the completion of the main objectives. However, if the player does not reach any main point, stopping somewhere on the road, he is faced with a minor event, where he will receive some minor bonus or penalty, or a neutral event. Thus, even along the way, some occurrences can be completed, which emulates, to a lesser extent, some of the stories of wandering knights. These minor events, however, are random, not depending on where the character stopped as the main events. Above all, these minor events help to establish the game's ambience and serve to bridge the gap between central events.

At events (especially the main ones, but also among the minors), it is common for the attributes and abilities of the characters to help define the direction of the story. This happens through what is normally called in RPGs "tests", dice rolls that determine the success or failure of the character in a given action. In this case, when the player is faced with an event in which there are chances of success or failure, normally the player will roll dice, rolling as many dice as there are points in the related attribute. The character will obtain success for each die that 
results in four, five or six. This means that, even in unfavourable situations, there are still reasonable chances of success $(50 \%)$. For each point above that, the chances of obtaining at least one success increase considerably, albeit in gradually lower values. In several smaller events, a single success is sufficient to be successful, but in major events, it may be necessary for the player to obtain several successes to obtain the best possible results. On the other hand, smaller events, being random, have a great chance of putting players in unfavourable situations, where they have little dice to roll, while main events are fixed, allowing players to choose the most appropriate people for each task and have greater chances of achieving multiple successes. In addition to events that require testing, there are also fixed events, especially between minor events. In these events, there is no specific roll to be made, only a fixed result to be obtained, which can be either positive or negative. These results can vary between obtaining bonuses or penalties on attributes, obtaining some extra alternative when visiting the main event or even something neutral (with no direct effects on the story, just as a setting). In these events, multiple different results may occur (especially in main events in this category), but in this case, the variation occurs through the character fulfilling specific conditions. It is possible, for example, that a certain challenge can only be won by someone who has a certain artefact, or who is particularly brave (in this case, having a certain value of bravery, without necessarily requiring a roll). Such events allow the creation of specific conditions to fulfil the main objectives, or perhaps to achieve a specific unfolding of the story, offering tools to adapt some specific legends.

The game is designed using, except for the board, almost exclusively cards. In this way, it is possible to create so many cards for the characters (who do not need much space for the few game characteristics they have), and the events also work better through this system, especially the smaller ones. In this way, players, at the start of the game, separate their players' cards, the cards from the main events (which will be face down while the players are not 
conducting their events) and place the random event cards in a deck, from which a card will be drawn at the end of each character's move. Thus, it is relatively easy to separate the stories (each with its deck of event cards) and also to make multiple copies of these stories. It is also easier to record which events were or were not held in the story (with the one who completed the event keeping the card to themselves) and offering a certain uniformity in the game. Besides, it is interesting to mention that the game is also thought to be relatively easy for players to assemble their own stories and characters if they so wish. Therefore, this flexibility also allows players to have their responsive attitude to the game, adding their narratives to it. This strategy was made considering the possibility of being used in a didactic project, where students, after having greater contact with the legends, adapt it to the format of the game. In the case of a game that remembers the Arthurian legends, eight characters were selected to be the playable characters by default in the game. The choice of eight characters was since it is a very recurring number of players in board games, possibly to prevent the excess from disturbing the gameplay of each one. In this way, even if it is possible to have more knights, as the standard format of the game, these eight were selected, leaving the option for players to try to recreate their favourite knights in the game format in case they have not been portrayed. With that in mind, the eight selected knights were: Arthur, Lancelot, Tristan, Gareth, Galahad, Gawain, Ector and Kay. All the characters were selected because they have remarkable relevance in some part of the story. Having defined the characters, it is worth discussing their main representation in the game, in the form of their game characteristics, their attributes and abilities. The focus in establishing the attributes was to try to determine the main characteristics that could define the ideals of chivalry inLe Morte d'Arthur.

Based on these criteria, it is appropriate to distribute the attributes among the characters. In general, the characters can be divided into two categories: specialists and generalists. Specialists would be those knights who are the epitome of one of these characteristics, among 
them Tristan (representing courteous love), Galahad (Catholic ideals) or Gareth (loyalty, especially to his companions). These are the characters that have their focus attribute at 5, at the cost of other lower attributes. In contrast, generalist characters usually have one or two attributes at a value of 4 or 3 but make up for it by not having low attributes. As the main characters in this category, we can mention Lancelot (in his dilemma between courteous love and loyalty), Arthur (representing several ideals of chivalry, but without being able to incorporate a single one perfectly) or Gawain (which despite his loyalty, could be attributed as one of the main causes, albeit unconsciously, for the fall of its king). Its characteristics can be seen in the table below:

\begin{tabular}{|c|c|c|c|}
\hline Character & Role & Role Main attributes & Weak attributes \\
\hline Arthur & Generalist & Bravery and Faith & Cumning \\
\hline Ector & Generalist & Loyalty and Cumning & Bravery \\
\hline Galahad & Specialist & Faith & $\begin{array}{l}\text { Courtesy and } \\
\text { Cumning }\end{array}$ \\
\hline Gareth & Specialist & Loyalty & Bravery and Faith \\
\hline Gawain & Generalist & Courage and Loyalty & Courtesy \\
\hline Kay & Generalist & Courtesy and Faith & Loyalty \\
\hline Lancelot & Generalist & Loyalty and Courtesy & Faith \\
\hline Tristan & Specialist & Courtesy & Bravery and Loyalty \\
\hline
\end{tabular}

Image 2: Characters and their game characteristics. Source: designed by the authors

Finally, there are also skills. These are representations of the main characteristics of these individuals, making them more unique than just the distribution of their attributes. In general, skills serve to strengthen you in your particular role, whether making it more versatile or specializing it. To build his characters, the teacher must know the literary work and apply in the best way the information it transmits to him about the characters. Another possibility is to build these attributes together with the students in another opportunity before the moment of playing the game. 


\section{Some Considerations}

It is worth remembering that the remediation process is a process of choices. Choices both for the format of the game and in terms of what the teacher will want to remedy. Therefore, the idea is to focus on what appears to be the most central topics for analysis of literary narrative. Additionally, there was also the choice of the game's genre. The choice for a board game, the wider choice, was born out of practicality more than anything.

The choice of using cards combined with the board also offers some benefits, in particular with a problem with a first version of the game where the information needed to be shuffled in a booklet, which made the process of searching for events relatively complex. With this, an extra benefit was also born, in the form of the ability to include illustrations, which allows exploring the narratives also from the visual arts side, if desired. With that, it is also worth mentioning that, although this version of the game based onLe Morte d'Arthur is presented in this article as an example, tests have already been carried out with it during the Interactive Show at UFRGS 2019, which allowed trying several aspects of the game in practice. During the Exhibition, it was possible to test how feasible the proposal was in the state in which it was presented, for which we had particularly positive results. Not only were there no problems with the time constraints, but the game also brought positive reactions from the audience that interacted with the project. Although due to the circumstances, it was difficult to test it with large groups, there was a reasonable number of tests with small groups of players, and it was possible to estimate from this how the game would work in larger groups.

Thus, it can be said that this article and, more effectively, this proposal to create RPG games that address literary themes in the classroom is also the result of the collaboration of countless people, who gave their opinions throughout the creation process, presenting both problems and solutions. Just as a game is a collective process, where all players contribute to 
a pleasant experience, the same can be said of the development of this proposal. In the same way as playing a game, this project was the result of the collaboration of many people, and, certainly, it helped to make the process much more fun, as well as making it more productive. Finally, we cannot fail to emphasize, once again, the relevance that games have in our daily lives. And, as Jesper Juul (2011) reminds us, the act of playing a game always has an impact on improving our repertoire of skills and the challenge of those who intend to develop a game is to create a product that instigates the pre-existing skills and drives their improvement during the game.

\section{Acknowledgements}

This work was carried out with the support of the National Council for Scientific and Technological Development (CNPq) and the Dean of Extension of the Federal University of Rio Grande do Sul (PROREXT / UFRGS). 


\section{Works Cited}

BOLTER, J. D; GRUSIN, R. Remediation: understanding new media. Cambridge: MIT Press, 1999.

FRASCA, Gonzalo. Ludologists love stories, too: notes from a debate that never took place. IN: COPIER, Marinka; RAESSENS, Joost (Orgs.). Level-up: digital games research conference. Utrecht: Utrecht University, 2003a.

FRASCA, Gonzalo. Simulation versus narrative. IN: WOLF, Mark; PERRON, Bernard (Orgs.). The video game theory reader. New York: Routledge, $2003 \mathrm{~b}$.

FRYE, Northrop. Anatomy of criticism. Princeton: Princeton University Pres, 1973.

GYGAX, G; ARNESON, D. Dungeons \& Dragons. Seattle: Wizards of the Coast, 2003.

HUIZINGA, Johan. Homo ludens. London: Routledge \& Kegan Paul, 1980.

ISER, Wolfgang. O jogo do texto. IN: Lima, Luiz Costa (org.). A Literatura e o leitor: textos de estética da recepção - Hans Robert Jauss et al. Rio de Janeiro: Paz e Terra, 2011.

JUUL, J. Half-real: Video Games between Real Rules and Fictional Worlds. Cambridge; MIT Press, 2011.

MALORY, T.; BUDIN, S, L. Le Morte d'Arthur: King Arthur and the Knights of the Round Table. San Diego: Canterbury Classics, 2015.

MCLUHAN, Herbert Marshall. Understanding media: the extensions of man. Berkeley: Gingko Press, 2013.

MORIARTY, J. Scotland Yard: 221B Baker Street: the master detective game. Gammon Games, 1975. 